\title{
Pengaruh Pendidikan, Pelatihan, dan Penempatan Kerja Terhadap Kinerja Karyawan Division Operation 2 PT. Semen Baturaja (Persero) Tbk
}

\author{
Daniel Ortega Situmorang ${ }^{1}$, Luis Marnisah², Fakhry Zamzam ${ }^{3}$ \\ ${ }^{1}$ Program Magister Universitas IGM, danielortegasitumorang@gmail.com \\ 2Program Magister Universitas IGM, luismarnisah@uigm.ac.id \\ 3Program Magister Universitas IGM, fakhry@ugim.ac.id
}

\begin{abstract}
ABSTRAK
Tujuan dari penelitian ini untuk mengetahui seberapa besar pengaruh variabel Pendidikan $\left(X_{1}\right)$, Pelatihan $\left(X_{2}\right)$, dan Penempatan Kerja $\left(X_{3}\right)$ baik secara individu maupun secara bersama-sama terhadap kinerja karyawan $(Y)$ untuk mengetahui variabel apa yang mempunyai pengaruh paling dominan terhadap kinerja karyawan Division Operation 2 PT. Semen Baturaja (Persero) Tbk. Metode pengumpulan data melalui kuesioner yang telah dibagikan. Sampel penelitian karyawan Division Operation 2 berjumlah 110 orang. Metode analisis yang digunakan adalah analisis regresi linear berganda. Hasil perhitungan untuk nilai regresi berganda diperoleh angka koefisien determinasi sebesar 0,511 yang artinya kinerja karyawan Division Operation PT. Semen Baturaja (Persero) Tbk dipengaruhi oleh pendidikan $\left(X_{1}\right)$, pelatihan $\left(X_{2}\right)$, dan penempatan kerja $\left(X_{3}\right)$ sebesar $51,1 \%$, sedangkan sisanya $49,9 \%$ dipengaruhi oleh variabel lain. Dari hasil uji regresi didapatkan hasil perhitungan nilai thitung dibandingkan dengan nilai tabel sebesar 1,981 disimpulkan bahwa variabel pendidikan dan pelatihan dengan nilai thitung dimensi pendidikan $\left(X_{1}\right) 2,465$, pelatihan $\left(X_{2}\right) 5,252$ sehingga memiliki pengaruh positif dan signifikan terhadap kinerja karyawan sedangkan untuk penempatan kerja $\left(X_{3}\right)$ memiliki thitung 1,129 sehingga tidak memiliki pengaruh positif dan signifikan terhadap kinerja karyawan Division Operation 2 PT. Semen Baturaja (Persero) Tbk. Pengujian secara simultan variabel $X$ terhadap variabel $Y$ yang membandingkan nilai $F_{\text {hitung }}$ dengan $F_{\text {tabel }}$ dimana $F_{\text {hitung }}$ $36,939>F_{\text {tabel }} 3,08$ sehingga variabel pendidikan $\left(X_{1}\right)$, pelatihan $\left(X_{2}\right)$, dan penempatan kerja $\left(X_{3}\right)$ memiliki pengaruh positif dan signifikan terhadap kinerja karyawan Division Operation 2 PT. Semen Baturaja (Persero) Tbk. Maka strategi untuk meningkatkan kinerja karyawan dapat dilakukan dengan meningkatkan kompetensi melalui pelatihan karyawan, kesesuaian pendidikan yang telah dicapai, dan selalu melakukan pekerjaan sesuai dengan standard operating procedure yang sudah ada.
\end{abstract}

Kata Kunci: Pendidikan, Pelatihan, Penempatan Kerja, dan Kinerja Karyawan

\begin{abstract}
Purpose of this study is to find out how much influence the variabel of education $\left(X_{1}\right)$, training $\left(X_{2}\right)$, and work placement $\left(X_{3}\right)$ both individually and collectively on employee performance $(Y)$ to find out what variables have an influence most dominant on the performance of employees of Division Operation 2 PT. Semen Baturaja (Persero) Tbk. The method of collecting data through questionnaires that have been distributed. The research sample of Division Operation 2's employees are 110 people. Method of analysis used multiple linear regression. The result of the calculation to the value obtained multiple regression coefficient of determination is 0,511 which means that the performance of staff at Division Operation 2 PT. Semen Baturaja (Persero) Tbk is affected by the determination of education, training, and work placement are $51,1 \%$ while the remaining $49,9 \%$ is influenced by other variables. From the test results obtained regression calculation results $t_{\text {count }}$ compared with table value of 1.981 concluded that the variabel of Education and Training with $t_{\text {count }}$ education $\left(X_{1}\right) 2.465$, training $\left(X_{2}\right) 5.252$ so as to have a positive influence the employee's performance while work placement $\left(X_{3}\right)$ has $t_{\text {count }} 1.129$ that has no effect on the employee's performance at Division Operation 2 PT. Semen Baturaja (Persero) Tbk. Simultaneous testing of variabel $X$ to variabel $Y$ simultane ously comparing the value $F_{\text {count }}$ with $F_{\text {table }}$ where $F_{\text {count }} 36.939>F_{\text {table }} 3.08$ that education $\left(X_{1}\right)$, training $\left(X_{2}\right)$, work placement $\left(X_{3}\right)$ have an positive influence on the employee's performance at Division Operation 2 PT. Semen Baturaja (Persero) Tbk. So, the strategy to improve employee performance can be done by increasing competency through employee training, conformity of education that has been achieved, and always doing work in accordance with existing standard operating procedures.
\end{abstract}

Key Words: Education, Training, Work Placement, dan Employee's Performance 


\section{A. PENDAHULUAN}

Keberhasilan dalam mencapai tujuan perusahaan tentunya tidak hanya ditentukan oleh besarnya dana yang dimiliki, teknologi yang digunakan, ataupun sarana dan prasarana yang terdapat pada suatu perusahaan, akan tetapi ada hal yang paling menentukan dalam penyatuan faktor yang ada dalam perusahaan tersebut yaitu faktor sumber daya manusia. Faktor inilah yang menggerakan seluruh faktor-faktor yang dimiliki perusahaan dalam rangka proses pencapaian tujuan perusahaan.

Sumber daya manusia juga memiliki peran penting bagi perusahaan, karena sumber daya manusia merupakan kombinasi antara tenaga, fisik, ide, bakat, pengetahuan, kreatifitas, dan keterampilan yang dibutuhkan untuk menggerakan perusahaan. Patut disadari bahwa karyawan merupakan sumber daya langsung yang terlibat dalam menjalankan kegiatan perusahaan. Kinerja seseorang karyawan merupakan awal yang sangat penting bagi terciptanya kinerja perusahaan.

Untuk itu, setiap perusahaan harus tepat dalam mencari sumber daya manusia, dan ada beberapa kriteria yang harus dipenuhi, salah satunya pendidikan.Pendidikan merupakan faktor yang perlu diperhatikan oleh suatu organisasi atau perusahaan. Dengan pendidikan dapat diperoleh gambaran tentang pengetahuan dan ketrampilan yang dimiliki tenaga kerja.Di division operation 2 sendiri mempunyai beragam tingkat pendidikan sebagai berikut:

Tabel Data Pegawai Division Operation 2 Berdasarkan Tingkat Pendidikan

\begin{tabular}{|c|l|c|}
\hline No & \multicolumn{1}{|c|}{ Tingkat Pendidikan } & Jumlah Karyawan \\
\hline 1 & Strata 2 & 1 \\
\hline 2 & Strata 1 & 42 \\
\hline 3 & Diploma & 49 \\
\hline 4 & SLTA / SMA & 61 \\
\hline & Total & 153 \\
\hline
\end{tabular}

Sumber: Division Human Resource , 2019

Dari tabel kita melihat Iulusan terbanyak adalah tingkat pendidikan SLTA / SMA sederajat dengan jumlah 61 orang, diikuti dengan lulusan Diploma sebanyak 49 orang, lulusan strata 1 sebanyak 42 orang, dan lulusan yang paling sedikit adalah tingkat pendidikan strata 2 sebanyak 1 orang.
Seiring dengan pendidikan, pelatihan pun menjadi hal yang penting dalam peningkatan keterampilan karyawan. Hal ini untuk meningkatkan kualitas angkatan kerja, untuk menghadapi perubahan yang berkelanjutan dan untuk menghadapi teknologi yang terus berkembang.

Berikut jenis pelatihan yang diikuti karyawan Division Operation 2: 
Tabel Jenis Pelatihan yang Diikuti Karyawan Division Operation 2

\begin{tabular}{|c|l|c|c|}
\hline No & \multicolumn{1}{|c|}{ Jenis Pelatihan } & Tanggal Pelatihan & $\begin{array}{c}\text { Jumlah Peserta } \\
\text { Diklat }\end{array}$ \\
\hline 1 & Sharing Knowledge & Juni 2018 & 30 \\
\hline 2 & IHT User Acceptance Test (UAT) SAP & Juli 2018 & 77 \\
\hline 3 & Shaft Alignment & Agustus 2018 & 14 \\
\hline 4 & Pengenalan Alat Ukur & Desember 2018 & 20 \\
\hline 5 & $\begin{array}{l}\text { Safety Leadership Program Key Issue } \\
\text { dan Strategy }\end{array}$ & Januari 2019 & 1 \\
\hline 6 & $\begin{array}{l}\text { Safety Leadership Program Mengelola } \\
\text { Keselamatan }\end{array}$ & Februari 2019 & 6 \\
\hline 7 & $\begin{array}{l}\text { Hazard Identification Risk Assessment } \\
\text { \& Control }\end{array}$ & Februari 2019 & 3 \\
\hline 8 & Fire Safety Management & Februari 2019 & 3 \\
\hline 9 & $\begin{array}{l}\text { Penyediaan Bahan Baku ( Alur Proses } \\
\text { dan Pemeliharaan) }\end{array}$ & Maret 2019 & 10 \\
\hline 10 & Proses Pembuatan Semen & Februari 2019 & 10 \\
\hline 11 & $\begin{array}{l}\text { Pengenalan equipment area kiln dan } \\
\text { pengenalan equipment area raw mill }\end{array}$ & Juli 2019 & 24 \\
\hline 12 & Safety Leadership Program & Agustus 2019 & 17 \\
\hline 13 & Training safety leadership & September 2019 & 3 \\
\hline 14 & Training BRC & $\begin{array}{c}\text { Oktober- } \\
\text { Desember 2019 }\end{array}$ & 129 \\
\hline
\end{tabular}

Sumber: Department Learning Academy, 2019

Dari tabel diatas menunjukan jenis pelatihan yang diikuti karyawan Division Operation 2 selang tahun 2018-2019 yang menunjukan bahwa pada tahun 2018 dari jumlah karyawan 151 orang, yang mengikuti pelatihan dengan jumlah terbanyak hanya 77 orang, dan selama tahun 2018 perusahaan hanya mengadakan pelatihan sebesar 4 jenis pelatihan. Pada tahun 2019, yang mengikuti pelatihan dengan jumlah terbanyak 129 orang dan selama tahun 2019 perusahaan sudah mengadakan pelatihan sebesar 10 jenis pelatihan. Disini kita melihat masih kurangnya pelatihan yang meningkatkan keahlian dan keterampilan yang sesuai dengan unit kerja yang ditempatkan sekarang.

Selain dari pendidikan dan pelatihan, faktor yang dapat mempengaruhi kinerja karyawan adalah penempatan kerja karena merupakan faktor penting yang dapat menghasilkan pendayagunaan sumber daya manusia (SDM) yang optimal bagi perusahaan sehingga dapat tercapainya tujuan perusahaan.

Penempatan kerja karyawan yang baik dilakukan perusahaan dilihat dari latar belakang pendidikan dan pengalaman kerja karyawan, pengalaman kerja merupakan kunci pembuka untuk menciptakan prestasi kerja yang baik bagi perusahaan, dengan adanya latar belakang pendidikan dan pengalaman kerja dapat menempatkan karyawan sesuai dengan persyaratan jabatan sehingga dapat bekerja dengan baik dan berprestasi. Dalam penempatan karyawan di divisi operation 2 terdapat beberapa karyawan ditempatkan di unit kerja yang berbeda dengan latar belakang pendidikan mereka, bahkan tidak sesuai dengan pengalaman kerja 
sebelumnya, sehingga diduga adanya pengaruh terhadap kinerja karyawan itu sendiri.

Berdasarkan uraian di atas peneliti memandang perlu untuk mengadakan penelitian tentang "Pengaruh Pendidikan, Pelatihan, dan Penempatan Kerja terhadap Kinerja Karyawan Division Operation 2 PT. Semen Baturaja (Persero) Tbk"

\section{B. KAJIAN TEORI}

1. Teori Pendidikan

Menurut Melmambessy Moses (2012) dalam hasibuan pendidikan merupakan indikator yang mencerminkan kemampuan seseorang untuk dapat menyelesaikan suatu pekerjaan

\section{Teori Pelatihan}

Menurut Wirawan (2015), pelatihan adalah pengembangan sumber daya manusia yang dirancang khusus untuk mengembangkan pengetahuan, ketrampilan, kompetensi, sikap dan perilaku pegawai dalam rangka mengembangkan kinerja para pegawai dalam rangka melaksanakan pekerjaannya yang sedang mereka lakukan sekarang.

\section{Teori Penempatan Kerja}

Penempatan karyawan adalah penugasan seseorang pada suatu jabatan yang sesuai dengan keahlian dan keterampilan yang dimilikinya. Penempatan merupakan penugasan atau penugasan kembali dari seseorang karyawan pada sebuah pekerjaan baru menurut Mangkuprawira (2009).

\section{Teori Kinerja}

Definisi kinerja yang disampaikan oleh Dale Timpe (2002) dalam Fakhrizal et al. (2012), bahwa "kinerja adalah tingkat prestasi seseorang atau karyawan dalam suatu organisasi atau perusahaan yang dapat meningkatkan produktifitas"

\section{Penelitian Sebelumnya}

David Harly Weol (2015), dalam penelitiannya yang berjudul Pengaruh Lingkungan Kerja, Pelatihan, dan Penempatan Terhadap kinerja Pegawai di Dinas Pendidikan Nasional Provinsi Sulawesi Utara. Tujuan penelitian ini yaitu untuk mengungkap Pengaruh lingkungan kerja, pelatihan dan penempatan terhadap kinerja pegawai di Dinas Pendidikan Nasional Sulawesi Utara. Sampel yang diambil sebanyak 65 responden. Metode analisis yang digunakan regresi linier berganda. Hasil penelitian menunjukkan bahwa Lingkungan kerja, pelatihan, dan penempatan berpengaruh secara positif dan signifikan terhadap kinerja pegawai.

Oswald H. F. Pokatong (2015), dalam penelitiannya yang berjudul Analisis Kompetensi, Penempatan dan Lingkungan Kerja Terhadap Kinerja Pegawai PT. PLN (Persero) Wilayah Suluttenggo Area Manado. Penelitian ini bertujuan untuk mengetahui pengaruh kompetensi, penempatan dan lingkungan kerja terhadap kinerja pegawai PT. PLN (Persero) Wilayah Suluttenggo Area Manado. Jumlah sampel sebanyak 60 responden. Metode analisis yang digunakan regresi liner berganda. Hasil analisis menunjukkan bahwa kompetensi, penempatan dan lingkungan kerja berpengaruh terhadap kinerja pegawai PT. PLN (Persero) Wilayah Suluttenggo Area Manado.

Turere (2013) dengan judul pengaruh pendidikan dan pelatihan terhadap peningkatan kinerja karyawan pada Balai Pelatihan Teknis Pertanian Kalasey. Jumlah sampel dalam penelitian ini adalah 50 orang, 
dengan menggunakan metode analisa regresi linear berganda. Hasil penelitian menunjukkan bahwa secara bersama-sama (simultan) maupun secara terpisah (parsial) variabel pendidikan $\left(\mathrm{X}_{1}\right)$ dan pelatihan $\left(\mathrm{X}_{2}\right)$ mempunyai pengaruh signifikan terhadap kinerja karyawan.

\section{METODE PENELITIAN \\ 1. Populasi Penelitian Menurut Sugiyono}

(2016)

Populasi adalah wilayah generalisasi yang terdiri atas objek/subjek yang mempunyai kualitas dan karakteristik tertentu yang ditetapkan oleh peneliti untuk dipelajari dan kemudian ditarik kesimpulannya. Populasi dalam penelitian ini sebanyak 153 karyawan.

\section{Sampel Penelitian}

Menurut Sugiono (2016) sampel adalah bagian dari jumlah karakteristik yang dimiliki oleh populasi dan harus bersifat representatif. Besarnya sample yang digunakan menggunakan rumus Slovin (Umar, 2008) adalah 110 orang.

\section{Rancangan Instrumen Penelitian}

a. Uji Validitas Instrumen

Uji validitas adalah uji yang digunakan untuk menunjukkan sejauh mana alat ukur yang digunakan dalam suatu mengukur apa yang diukur. Ghozali (2009)

b. Uji Reliabilitas Instrumen

Sugiharto dan Situnjak (2006) menyatakan bahwa reliabilitas menunjuk pada suatu pengertian bahwa instrumen yang digunakan dalam penelitian untuk memperoleh informasi yang digunakan dapat dipercaya sebagai alat pengumpulan data dan mampu mengungkap informasi yang sebenarnya di lapangan. Tinggi rendahnya reliabilitas, secara empirik ditunjukkan oleh suatu angka yang disebut nilai koefisien reliabilitas. Reliabilitas yang tinggi ditunjukkan dengan nilai rxx mendekati angka 1. Kesepakatan secara umum reliabilitas yang dianggap sudah cukup memuaskan jika $\geq 0.700$.

\section{Rancangan Pengujian Asumsi Klasik}

a. Uji Normalitas

Uji normalitas bertujuan untuk menguji apakah dalam model regresi, variabel pengganggu atau residual memiliki distribusi normal. Seperti diketahui bahwa uji $t$ dan $F$ mengasumsikan bahwa nilai residual mengikuti distribusi normal. Kalau asumsi ini dilanggar maka uji statistik menjadi tidak valid untuk jumlah sampel kecil. Ada dua cara untuk mendeteksi apakah residual berdistribusi normal atau tidak yaitu dengan analisis grafik dan uji statistik. Untuk menguji apakah data berdistribusi normal atau tidak dilakukan uji statistik Kolmogorov-Smirnov Test. Residual berdistribusi normal jika memiliki nilai signifikansi $>0,05$ (Imam Ghozali, 2011). Dalam penelitian ini, pengukuran uji normalitas akan dilakukan dengan menggunakan alat bantu SPSS (Statistical Product and Service Solution) versi 25.

b. Uji Multikolinearitas

Menurut Ghozali (2016) pada pengujian multikolinearitas bertujuan untuk mengetahui apakah model regresi ditemukan adanya korelasi antar variabel independent atau variable bebas. Efek dari multikolinearitas ini adalah menyebabkan tingginya variabel pada sampel. $\mathrm{Hal}$ 
tersebut berarti standar error besar, akibatnya ketika koefisien diuji, t-hitung akan bernilai kecil dari t-tabel. Hal ini menunjukkan tidak adanya hubungan linear antara variabel independen yang dipengaruhi dengan variabel dependen.

Untuk menemukan terdapat atau tidaknya multikolinearitas pada model regresi dapat diketahui dari nilai toleransi dan nilai variance inflation factor (VIF). Nilai Tolerance mengukur variabilitas dari variabel bebas yang terpilih yang tidak dapat dijelaskan oleh variabel bebas lainnya. Jadi nilai tolerance rendah sama dengan nilai VIF tinggi, dikarenakan VIF = 1/tolerance, dan menunjukkan terdapat kolinearitas yang tinggi. Nilai cut off yang digunakan adalah untuk nilai tolerance 0,10 atau nilai VIF diatas angka 10.

c. Uji Heterodastisitas

Salah satu cara untuk melihat adanya problem heteroskedastisitas adalah dengan melihat grafik plot antara nilai prediksi variabel terikat
(ZPRED) dengan residualnya (SRESID). Cara menganalisisnya adalah dengan melihat pola dari penyebaran titik-titik, jika tidak terdapat pola tertentu yang jelas,serta titik-titik tersebar di atas dan di bawah angka 0 pada sumbu $Y$, maka mengindikasikan tidak terjadi heteroskedastisitas.

d. Uji Autokorelasi

Uji autokorelasi yang dilakukan penelitian ini bertujuan untuk mengetahui apakah dalam sebuah model regresi linier ada korelasi antara kesalahan pengganggu pada periode $t$ dengan kesalahan pada periode t-1 (sebelumnya). Jika terjadi korelasi, maka dinamakan ada problem autokorelasi. Tentu saja model regresi yang baik adalah regresi yang bebas dari autokorelasi (Singgih Santoso, 2012). Pada prosedur pendeteksian masalah autokorelasi dapat digunakan besaran Durbin-Waston. Untuk memeriksa ada tidaknya autokorelasi, maka dilakukan uji Durbin-Watson dengan keputusan sebagai berikut:

Tabel Uji Statistik Durbin-Watson

\begin{tabular}{|c|c|}
\hline Nilai Statistik d & Hasil \\
\hline $0<d<d L$ & Ada auto korelasi positif \\
\hline$d L \leq d \leq d u$ & Ragu-ragu \\
\hline$d u \leq d \leq 4-d u$ & Tidak ada korelasi postitif / negatif \\
\hline $4-d u \leq d \leq 4-d L$ & Ragu-ragu \\
\hline $4-d L \leq d \leq 4$ & Ado korelasi negative \\
\hline
\end{tabular}

Sumber : Singgih Santoso, 2020

\section{Analisis Regresi Linier Berganda}

Analisis regresi berganda digunakan untuk menguji pengaruh dua atau lebih variabel independen terhadap variabel dependen. Adapun variabel dependen dalam penelitian ini adalah kinerja karyawan sedangkan variabel independennya adalah pendidikan, pelatihan, dan penempatan kerja.

a. Uji Hipotesis

Pengujian hipotesis dalam penelitian ini dilakukan dengan 
menganalisis nilai Probability $(\mathrm{P})$ dari hasil pengolahan data menggunakan SPSS dibandingkan dengan batasanstatistik yang dipersyaratkan, yaitu dibawah 0,05 dan nilai t hitung lebih besar dibandingkandengan tabel untuk hipotesis 1, 2, dan 3. Sedangkan untuk hipotesis 4 kriteria penerimaanhipotesis dengan melihat nilai probalitas $<0,05$ dan nilai $F_{\text {hitung }}>$ dari $F_{\text {tabel. }}$.

b. Koefisien Determinasi (Adjusted $R$ Square)

Uji ini bertujuan untuk menentukan proporsi atau presentase total variasi dalam variabel terikat yang diterangkan oleh variabel bebas. Analisis yang digunakan adalah adalah regresi berganda, maka yang digunakan adalah Adjusted $R$ Square.

\section{HASIL DAN PEMBAHASAN}

1. Hasil Uji Instrumen Penelitian

Hasil pengujian validitas dan reliabilitas instrumen penelitian pada variabel pendidikan, pelatihan, dan penempatan kerja adalahsebagai berikut ini:

Tabel Uji Validitas Variabel Pendidikan $\left(\mathrm{X}_{1}\right)$

\begin{tabular}{|c|c|c|c|}
\hline Item Indicator & Corrected Item-Total Correlation & r-tabel $(\mathbf{N}=\mathbf{1 1 0})$ & Keterangan \\
\hline PD01 & 0,601 & 0.1874 & Valid \\
\hline PD02 & 0,74 & 0.1874 & Valid \\
\hline PD03 & 0,775 & 0.1874 & Valid \\
\hline PD04 & 0,537 & 0.1874 & Valid \\
\hline PD05 & 0,78 & 0.1874 & Valid \\
\hline PD06 & 0,794 & 0.1874 & Valid \\
\hline
\end{tabular}

Sumber : Data Primer yang diolah, 2020

Tabel Uji Validitas Variabel Pelatihan $\left(\mathbf{X}_{2}\right)$

\begin{tabular}{|c|c|c|c|}
\hline Item Indicator & $\begin{array}{c}\text { Corrected Item-Total } \\
\text { Correlation }\end{array}$ & r-tabel $(\mathbf{N}=110)$ & Keterangan \\
\hline PL01 & 0,687 & 0.1874 & Valid \\
\hline PL02 & 0,73 & 0.1874 & Valid \\
\hline PL03 & 0,383 & 0.1874 & Valid \\
\hline PL04 & 0,687 & 0.1874 & Valid \\
\hline PL05 & 0,737 & 0.1874 & Valid \\
\hline PL06 & 0,778 & 0.1874 & Valid \\
\hline PL07 & 0,72 & 0.1874 & Valid \\
\hline PL08 & 0,799 & 0.1874 & Valid \\
\hline PL09 & 0,766 & 0.1874 & Valid \\
\hline
\end{tabular}

Sumber : Data Primer yang diolah, 2020

Tabel Uji Validitas Variabel Penempatan Kerja $\left(X_{3}\right)$

\begin{tabular}{|c|c|c|c|}
\hline Item Indicator & $\begin{array}{c}\text { Corrected Item-Total } \\
\text { Correlation }\end{array}$ & r-tabel $(\mathbf{N}=\mathbf{1 1 0})$ & Keterangan \\
\hline PN01 & 0,669 & 0.1874 & Valid \\
\hline PN02 & 0,64 & 0.1874 & Valid \\
\hline
\end{tabular}




\begin{tabular}{|c|l|l|l|} 
PN03 & 0,752 & 0.1874 & Valid \\
\hline PN04 & 0,682 & 0.1874 & Valid \\
\hline PN05 & 0,592 & 0.1874 & Valid \\
\hline PN06 & 0,688 & 0.1874 & Valid \\
\hline PN07 & 0,598 & 0.1874 & Valid \\
\hline
\end{tabular}

Sumber : Data Primer yang diolah, 2020

Tabel Uji Validitas Kinerja Karyawan (Y)

\begin{tabular}{|c|c|c|c|}
\hline Item Indicator & $\begin{array}{c}\text { Corrected Item-Total } \\
\text { Correlation }\end{array}$ & r-tabel $\mathbf{( N = 1 1 0 )}$ & Keterangan \\
\hline KN01 & 0,781 & 0.1874 & Valid \\
\hline KN02 & 0,821 & 0.1874 & Valid \\
\hline KN03 & 0,736 & 0.1874 & Valid \\
\hline KN04 & 0,812 & 0.1874 & Valid \\
\hline KN05 & 0,851 & 0.1874 & Valid \\
\hline KN06 & 0,839 & 0.1874 & Valid \\
\hline KN07 & 0,745 & 0.1874 & Valid \\
\hline
\end{tabular}

Sumber : Data Primer yang diolah, 2020

Tabel Uji Reliabilitas Data

\begin{tabular}{|c|c|c|c|}
\hline Variabel & Alpha & $\begin{array}{c}\text { Cronbach } \\
\text { Alpha }\end{array}$ & Reliabilitas \\
\hline Pendidikan (X1) & 0,786 & 0,7 & Reliabel \\
\hline Pelatihan (X2) & 0,859 & 0,7 & Reliabel \\
\hline Penempatan Kerja (X3) & 0,777 & 0,7 & Reliabel \\
\hline Kinerja Karyawan (Y) & 0,901 & 0,7 & Reliabel \\
\hline
\end{tabular}

Sumber : Data Primer yang diolah, 2020

\section{Hasil Uji Asumsi Klasik}

a. Uji Normalitas

Hasil scatter plot untuk menguji normalitas adalah sebagai berikut:

Tabel Hasil Uji Normalitas

\begin{tabular}{|c|c|c|}
\hline \multicolumn{3}{|c|}{ One-Sample Kolmogorov-Smirnov Test } \\
\hline & & $\begin{array}{c}\text { Unstandardized } \\
\text { Residual }\end{array}$ \\
\hline \multicolumn{2}{|l|}{$\mathrm{N}$} & 110 \\
\hline \multirow[t]{2}{*}{ Normal Parameters ${ }^{a, b}$} & Mean & .0000000 \\
\hline & Std. Deviation & .05506097 \\
\hline \multirow[t]{3}{*}{ Most Extreme Differences } & Absolute & .049 \\
\hline & Positive & .049 \\
\hline & Negative & -.040 \\
\hline \multicolumn{2}{|l|}{ Test Statistic } & .049 \\
\hline \multicolumn{2}{|l|}{ Asymp. Sig. (2-tailed) } & $.200^{\mathrm{c}, \mathrm{d}}$ \\
\hline \multicolumn{3}{|l|}{ a. Test distribution is Normal. } \\
\hline \multicolumn{3}{|l|}{ b. Calculated from data. } \\
\hline
\end{tabular}

Sumber : Data Primer yang diolah, 2020 
Jika melihat hasil estimasi uji Kolmogorov-Smirnov diatas, dimana nilai Asymp. Sig. (2-tailed) sebesar 0,200 dan nilai tersebut berada diatas nilai $P$-Value $(\alpha)$ yaitu sebesar 0,05 , maka dapat disimpulkan bahwa data pada penelitian ini distribusi datanya terdistribusi dengan normal. b. Uji Multikolinearitas

Uji multikolinearitas dalam penelitian ini dilihat dari nilai tolerance atau variance inflation factor (VIF). Adapun perhitungan estimasi nilai tolerance atau VIF dengan program SPSS 25 dapat dilihat pada tabel berikut:

Tabel Hasil Uji Multikolinearitas

\begin{tabular}{|c|c|c|c|c|c|c|c|}
\hline \multicolumn{8}{|c|}{ Coefficients $^{\mathrm{a}}$} \\
\hline \multirow[b]{2}{*}{ Model } & \multicolumn{2}{|c|}{$\begin{array}{c}\text { Unstandardized } \\
\text { Coefficients }\end{array}$} & \multirow{2}{*}{\begin{tabular}{|c|}
$\begin{array}{c}\text { Standardized } \\
\text { Coefficients }\end{array}$ \\
Beta
\end{tabular}} & \multirow[b]{2}{*}{ t } & \multirow[b]{2}{*}{ Sig. } & \multicolumn{2}{|c|}{$\begin{array}{l}\text { Collinearity } \\
\text { Statistics }\end{array}$} \\
\hline & B & Std. Error & & & & Tolerance & VIF \\
\hline 1 (Constant) & .174 & .042 & & 4.126 & .000 & & \\
\hline Pendidikan & .159 & .064 & .214 & 2.465 & .015 & .610 & 1.640 \\
\hline Pelatihan & .604 & .115 & .490 & 5.252 & .000 & .530 & 1.886 \\
\hline Penempatan & .108 & .096 & .116 & 1.129 & 261 & .434 & 2.304 \\
\hline
\end{tabular}

a. Dependent Variable: Kinerja

Sumber : Data primer yang diolah, 2020

Tabel diatas dapat diketahui bahwa nilai tolerance dari variabel $X_{1}$ sebesar 0,610 , variabel $X_{2}$ sebesar 0,530 , variabel $X_{3}$ sebesar 0,434 lebih besar dari 0,10 sedangkan nilai $\mathrm{VIF}$ dari variabel $X_{1}$ sebesar 1,640, variabel $X_{2}$ sebesar 1,886 , variabel $X_{3}$ sebesar 2,304 lebih kecil dari 5 . Berdasarkan hasil perhitungan di atas dapat dilihat bahwa nilai tolerance semua variabel bebas lebih besar dari 0,10 dan nilai VIF semua variabel bebas juga lebih kecil dari 10 sehingga tidak terjadi gejala korelasi pada variabel bebas. Sehingga dapat disimpulkan bahwa tidak adanya gejala multikolinearitas antar variabel bebas dalam model regresi. c. Uji Heteroskedastisitas

Uji heteroskedastisitas diuji dengan Scatterplot SPSS yaitu dengan melihat grafik plot antara nilai prediksi variabel terikat (ZPRED) dengan residualnya (SRESID). Apabila sebaran titik pada scatterplot menggambarkan sebaran titik yang menyebar secara maksimal dan tidak membentuk pola sebaran tertentu serta titik-titik tersebar di atas dan di bawah angka 0 pada sumbu $Y$ maka dalam model regresi tidak terjadi heteroskedastisitas. Berikut ini adalah gambar 1 yang menunjukkan estimasi matrik variabel. 


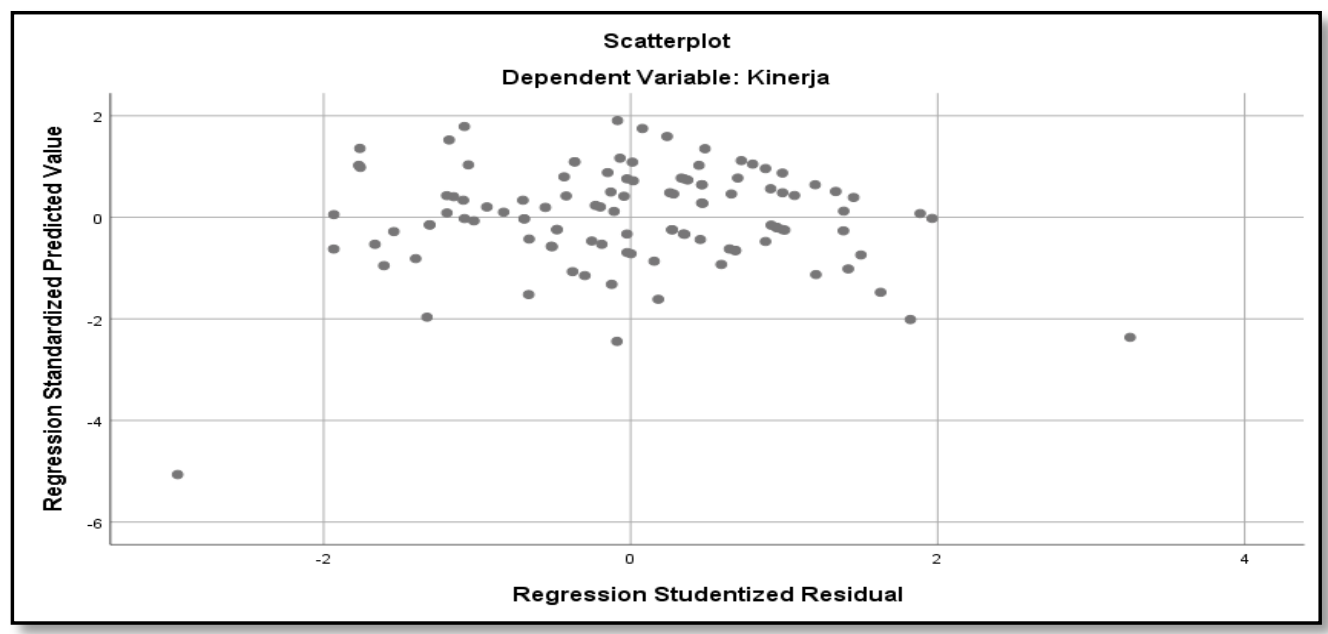

Sumber : Data primer yang diolah, 2020

\section{Gambar Hasil Uji Heterodastisitas}

Berdasarkan grafik scatterplot di atas dapat dianalisis $\mathrm{X}_{1}, \mathrm{X}_{2}$ dan $\mathrm{X}_{3}$ tidak terjadi heteroskedastisitas karena memiliki penyebaran titik-titik dimana tidak terdapat pola tertentu yang jelas, serta titik-titik tersebar diatas dan dibawah angka 0 pada sumbu $Y$. Dari pengamatan grafik diatas dapat disimpulkan bahwa dalam model regresi ini tidak terjadi
heteroskedastisitas.

d. Uji Autokorelasi

Salah satu cara untuk mendeteksi ada atau tidaknya autokorelasi dalam penelitian ini digunakan uji Durbin Watson (DW) dengan melihat DW test. Berikut adalah hasi DW Test.

Tabel Hasil Uji Autokorelasi

\begin{tabular}{|l|c|r|r|r|r|}
\hline \multicolumn{7}{|c|}{ Model Summary } \\
\hline Model & $\mathrm{R}$ & $\mathrm{R}$ Square & $\begin{array}{c}\text { Adjusted R } \\
\text { Square }\end{array}$ & $\begin{array}{c}\text { Std. Error of } \\
\text { the Estimate }\end{array}$ & Durbin-Watson \\
\hline 1 & $.715^{\mathrm{a}}$ & .511 & .497 & .05583 & 2.095 \\
\hline \multicolumn{7}{|l|}{ a. Predictors: (Constant), Penempatan, Pendidikan, Pelatihan } \\
\hline \multicolumn{7}{|l}{ b. Dependent Variable: Kinerja } \\
\hline
\end{tabular}

Sumber : Data primer yang diolah, 2020

Berdasarkan tabel uji autokorelasi diketahui untuk nilai $\mathrm{DW}=$ 2,095 dibandingkan dengan nilai tabel signifikansi $5 \%(0,05)$ dengan jumlah sampel 110 serta $k=3$, diperoleh nilai $\mathrm{dL}$ sebesar 3,110 dan hasil dU dari tabel $r=1.7455$. Jadi nilai DW lebih besar dari batas dU atau DW 2,095 >
1,7455, sehingga disimpulkan bahwa tidak terdapat autokorelasi.

\section{Regresi Linear Berganda}

Analisis data dalam penelitian ini menggunakan analisis regresi linier berganda. Analisis masing-masing variabel dijelaskan dalam uraian berikut: 
Tabel Hasil Koefisien Regresi Linear Berganda

\begin{tabular}{|c|c|c|c|c|c|c|c|c|}
\hline \multicolumn{9}{|c|}{ Coefficients $^{a}$} \\
\hline \multirow{2}{*}{\multicolumn{2}{|c|}{ Model }} & \multicolumn{2}{|c|}{$\begin{array}{l}\text { Unstandardized } \\
\text { Coefficients }\end{array}$} & \multirow{2}{*}{$\begin{array}{l}\text { Standardized } \\
\text { Coefficients } \\
\text { Beta }\end{array}$} & & \multirow[b]{2}{*}{ Sig. } & \multicolumn{2}{|c|}{$\begin{array}{c}\text { Collinearity } \\
\text { Statistics }\end{array}$} \\
\hline & & $\mathrm{B}$ & Std. Error & & & & Tolerance & VIF \\
\hline 1 & (Constant) & .174 & .042 & & 4.126 & .000 & & \\
\hline & Pendidikan & $.15 \varsigma$ & .064 & .214 & 2.465 & .015 & .610 & 1.64 \\
\hline & Pelatihan & .602 & .115 & .490 & 5.252 & .000 & .530 & 1.88 \\
\hline & Penempatan & $.10 \varepsilon$ & .096 & .116 & 1.129 & .261 & .434 & 2.304 \\
\hline
\end{tabular}

a. Dependent Variable: Kinerja

Sumber: Data primer yang diolah, 2020

Berdasarkan tabel di atas maka didapat persamaan regresi sederhana sebagai berikut:

$$
Y=0,174+0,159 X_{1}+0,604 X_{2}+0,108 X_{3}
$$

Interpretasi dari persamaan regresi berganda mengenai pengaruh variabel pendidikan $\left(X_{1}\right)$, pelatihan $\left(X_{2}\right)$ dan penempatan kerja $\left(X_{3}\right)$ terhadap variabel terikat yaitu kinerja karyawan (Y), dapat dijelaskan sebagai berikut:

a. Nilai konstanta sebesar 0,174 menunjukan bahwa variabel pendidikan $\left(\mathrm{X}_{1}\right)$, pelatihan $\left(\mathrm{X}_{2}\right)$, dan penempatan kerja $\left(X_{3}\right)$ dianggap tidak ada (nol) maka variabel kinerja karyawan Division Operation 2 PT. Semen Baturaja (Persero) Tbk sebesar 0,174 .

b. Koefisien regresi variabel pendidikan $\left(X_{1}\right)$ sebesar 0,159 . Artinya, apabila terdapat peningkatan variabel pendidikan sebesar satu satuan sementara variabel independen lainnya tetap maka kinerja karyawan Division Operation 2 PT. Semen Baturaja
(Persero) Tbk akan mengalami peningkatan sebesar 0,159 .

c. Koefisien regresi variabel pelatihan $\left(X_{2}\right)$ sebesar 0,604 . Artinya, apabila terdapat peningkatan variabel pelatihan sebesar satu satuan sementara variabel independen lainnya tetap maka kinerja karyawan Division Operation 2 PT. Semen Baturaja (Persero) Tbk akan mengalami peningkatan sebesar 0,604 .

d. Koefisien regresi variabel penempatan kerja $\left(X_{3}\right)$ sebesar 0,302 . Artinya, apabila terdapat peningkatan variabel pelatihan sebesar satu satuan sementara variabel independen lainnya tetap maka kinerja karyawan Division Operation 2 PT. Semen Baturaja (Persero) Tbk akan mengalami peningkatan sebesar 0,604.

\section{Hasil Uji Hipotesis}

Analisis data dalam penelitian ini menggunakan analisis regresi linier berganda. Analisis masing-masing variabel dijelaskan dalam uraian berikut: 
Tabel Hasil Regresi Linear Berganda

\begin{tabular}{|c|c|c|c|c|c|c|c|c|}
\hline \multicolumn{9}{|c|}{ Coefficients $^{a}$} \\
\hline \multirow{2}{*}{\multicolumn{2}{|c|}{ Model }} & \multicolumn{2}{|c|}{$\begin{array}{c}\text { Unstandardized } \\
\text { Coefficients }\end{array}$} & \multirow{2}{*}{$\begin{array}{c}\text { Standardized } \\
\text { Coefficients } \\
\text { Beta }\end{array}$} & \multirow[b]{2}{*}{$\mathrm{t}$} & \multirow[b]{2}{*}{ Sig. } & \multicolumn{2}{|c|}{$\begin{array}{c}\text { Collinearity } \\
\text { Statistics }\end{array}$} \\
\hline & & $\mathrm{B}$ & Std. Error & & & & Tolerance & VIF \\
\hline \multirow[t]{4}{*}{1} & (Constant) & .174 & .042 & & 4.126 & .000 & & \\
\hline & Pendidik & .159 & .064 & 214 & 2.465 & .015 & .610 & 1.640 \\
\hline & Pela & & .115 & .490 & 5.2 & & .530 & \\
\hline & Penempatan & .108 & .096 & .116 & 1.129 & 261 & .434 & 2.304 \\
\hline
\end{tabular}

a. Dependent Variable: Kinerja

Sumber : Data primer yang diolah, 2020

Pada pengujian hipotesis diperoleh hasil bahwa:

1. Berdasarkan hasil pengolahan data menggunakan SPSS versi 25.0 dengan Uji-t diketahui nilai signifikansi (siq) variabel pendidikan $\left(\mathrm{X}_{2}\right)$ adalah sebesar 0,15 dan untuk thitung sebesar 2,465 . Karena nilai sig $0.015<$ 0,05 dan thitung $2,465>t_{\text {tabel }}$ 1.98177, maka terbukti bahwa secara parsial pendidikan berpengaruh positif dan signifikan terhadap kinerja karyawan division operation 2 PT. Semen Baturaja (Persero), Tbk. Maka hipotesis $1 \quad\left(\mathrm{H}_{1}\right)$ disimpulkan bahwa $\mathrm{H}_{0}$ ditolak dan $\mathrm{H}_{1}$ diterima.

2. Berdasarkan hasil pengolahan data menggunakan SPSS versi 25.0 dengan Uji-t diketahui nilai signifikansi (siq) variabel pelatihan (X1) adalah sebesar 0,00 dan untuk thitung sebesar 5,252 . Karena nilai sig $0.00<$ 0,05 dan thitung 5,252 > tabel 1.98177, maka terbukti bahwa secara parsial pelatihan berpengaruh positif dan signifikan terhadap kinerja karyawan division operation 2 PT. Semen Baturaja (Persero), Tbk. Maka hipotesis $2 \quad\left(\mathrm{H}_{2}\right)$ disimpulkan bahwa $\mathrm{H}_{0}$ ditolak dan $\mathrm{H}_{2}$ diterima.

3. Berdasarkan hasil pengolahan data menggunakan SPSS versi 25.0 dengan Uji-t diketahui nilai signifikansi (siq) variabel penempatan kerja $\left(X_{3}\right)$ adalah sebesar 0,261 dan untuk thitung sebesar 1,129. Karena nilai sig $0,261>0,05$ dan thitung $1,129<$ tabel1.98177, maka terbukti bahwa secara parsial penempatan kerja tidak berpengaruh terhadap kinerja karyawan division operation 2 PT. Semen Baturaja (Persero) Tbk. Maka hipotesis $3 \quad\left(\mathrm{H}_{3}\right)$ disimpulkan bahwa $\mathrm{H}_{0}$ diterima dan $\mathrm{H}_{3}$ ditolak.

Untuk hasil pengujian hipotesis 4 , dapat dilihat dari tabel di bawah ini: 
Tabel Hasil Uji F

\begin{tabular}{|c|c|c|c|c|c|c|}
\hline \multicolumn{7}{|c|}{ ANOVA $^{\mathrm{a}}$} \\
\hline \multicolumn{2}{|c|}{ Model } & $\begin{array}{l}\text { Sum of } \\
\text { Squares }\end{array}$ & df & Mean Square & $\mathrm{F}$ & \\
\hline 1 & Regression & .345 & 3 & .115 & 36.939 & $.000^{\mathrm{b}}$ \\
\hline & Residual & .330 & 106 & .003 & & \\
\hline & Total & .676 & 109 & & & \\
\hline
\end{tabular}

Sumber : Data primer yang diolah, 2020

Dari tabel di atas dapat dilihat bahwa nilai signifikansi sebesar $0,000<0,05$ dan nilai $F_{\text {hitung }}$ sebesar $36,939>F_{\text {tabel }}$ 3,08 maka hipotesis 4 diterima. Artinya Pendidikan $\left(X_{1}\right)$, Pelatihan $\left(X_{2}\right)$, dan Penempatan Kerja $\left(X_{3}\right)$ memiliki pengaruh signifikan dan positif secara simultan terhadap Kinerja Karyawan
(Y) Division Operation 2 PT. Semen Baturaja (Persero) Tbk.

\section{Hasil Uji Koefisien Determinasi (R Square)}

Hasil uji koefisien determinasi atau $R$ square (R2) dengan menggunakan program SPSS 25.0 dapat dilihat pada tabel berikut:

Tabel Hasil Uji Koefisien Determinasi

\begin{tabular}{|l|c|r|c|c|r|}
\hline \multicolumn{5}{|c|}{ Model Summary } \\
\hline Model & $\mathrm{R}$ & R Square & $\begin{array}{c}\text { Adjusted R } \\
\text { Square }\end{array}$ & $\begin{array}{c}\text { Std. Error of } \\
\text { the Estimate }\end{array}$ & Durbin-Watson \\
\hline 1 & $.715^{\mathrm{a}}$ & .511 & .497 & .05583 & 2.095 \\
\hline a. Predictors: (Constant), Penempatan, Pendidikan, Pelatihan & \\
\hline \multicolumn{4}{|l|}{ b. Dependent Variable: Kinerja } \\
\hline
\end{tabular}

Sumber: Data primer yang diolah, 2020

Kontribusi yang diberikan oleh variabel pendidikan $\left(X_{1}\right)$, pelatihan $\left(X_{2}\right)$, dan penempatan kerja $\left(X_{3}\right)$ secara simultan terhadap kinerja karyawan $(\mathrm{Y})$ atau koefisien determinasi ( $R$ Square) adalah 0,511. Hal ini menunjukan bahwa $51,9 \%$ dari variabel pendidikan $\left(X_{1}\right)$, pelatihan $\left(X_{2}\right)$, dan penempatan kerja $\left(\mathrm{X}_{3}\right)$, sedangkan sisanya yaitu $49,1 \%$ diterangkan oleh variabel lain yang tidak diteliti dalam penelitian ini.

\section{E. KESIMPULAN DAN SARAN}

1) Kesimpulan

Dari analisis yang telah dilakukan dan dijabarkan pada bab-bab sebelumnya, maka dapat ditarik kesimpulan sebagai berikut : a. Pendidikan yang telah dicapai untuk meningkatkan keahlian dan pengetahuan dalam bekerja; berpengaruh secara positif dan signifikan terhadap kinerja karyawan Division Operation 2 PT. Semen Baturaja (Persero) Tbk yang berusaha mencapai hasil kerja yang baik.

b. Pelatihan yang ditujukan untuk meningkatkan kompetensi karyawan; berpengaruh secara positif dan signifikan terhadap kinerja karyawan Division Operation 2 PT. Semen Baturaja (Persero) Tbk yang berusaha mencapai hasil kerja yang baik.

c. Penempatan kerja yang pekerjaan dilakukan sesuai 
dengan standard operating procedure; tidak berpengaruh secara positif dan signifikan terhadap kinerja karyawan Division Operation 2 PT. Semen Baturaja (Persero) Tbk yang berusaha mencapai hasil kerja yang baik.

d. Pendidikan yang telah dicapai untuk meningkatkan keahlian dan pengetahuan dalam bekerja; pelatihan yang ditujukan untuk meningkatkan kompetensi karyawan; dan pekerjaan yang dilakukan sesuai dengan standard operating procedure secara simultan berpengaruh secara positif dan signifikan terhadap kinerja karyawan Division Operation 2 PT. Semen Baturaja (Persero) Tbk yang berusaha mencapai hasil kerja yang baik.

e. Variable tertinggi yang paling besar pengaruh terhadap kinerja adalah pelatihan.

2) Saran

a. PT. Semen Baturaja (Persero) Tbk disarankan untuk melakukan penyeleksian atau menempatkan karyawan di bidang pekerjaanya sesuai dengan ilmu pengetahuan yang dimiliki.

b. PT. Semen Baturaja (Persero) Tbk disarankan sebelum melaksanakan pelatihan perlu melakukan seleksi calon peserta pelatihan terlebih dahulu.

c. PT. Semen Baturaja (Persero) Tbk disarankan untuk menempatkan karyawan di unit kerja yang sesuai dengan pengalaman kerja sebelumnya.

d. Disarankan untuk PT. Semen Baturaja (Persero) Tbk untuk melakukan pengendalian agar karyawan dapat menyelesaikan pekerjaan dalam kurun waktu yang cepat.

\section{DAFTAR PUSTAKA}

Dale, T. (2002). Seri Manajemen Sumber Daya Manusia Kinerja (Kelima). PT Elex Media Komputindo.

Ghozali, I. (2016). Aplikasi Analisis Multivariete IBM SPSS. In Semarang, Universitas Diponegoro.

https://doi.org/10.1017/CBO9781 107415324.004

Ghozali, Imam. (2009). Aplikasi Multivariate dengan Program SPSS edisi III. Semarang: Badan Penerbit UNDIP. https://doi.org/10.1016/j.000o.201 7.11.003

Ghozali, Imam. (2013). Aplikasi Analisis Multivariete. In Badan Penerbit Universitas Dipenegoro.

Loindong, S., Mananeke, L., \& Pokatong, O. H. (2015). Analisis Kompetensi, Penempatan dan Lingkungan Kerja terhadap Kinerja Pegawai pada PT. PLN (Persero) Wilayah Suluttenggo Area Manado. Jurnal EMBA: Jurnal Riset Ekonomi, Manajemen, Bisnis Dan Akuntansi, 3(2). https://doi.org/10.35794/emba.v3i 2.8694

Mangkuprawira, S. (2009). Manajemen Sumber Daya Manusia. In Mycological Research.

Moses, M. (2012). Analisis Pengaruh Pendidikan, Pelatihan, dan Pengalaman Kerja terhadap Produktivitas Kerja Pegawai 
Dinas Pertambangan dan Energi Provinsi Papua . Analisis Pengaruh Pendidikan, Pelatihan, Dan Pengalaman Kerja Terhadap Produktivitas Kerja Pegawai Dinas Pertambangan Dan Energi Provinsi Papua ., 18-36.

Santoso, S. (2012). Panduan Lengkap SPSS Versi 20. In PT Elex Media Komputindo.

Sitinjak, T. J. \& S. (2006). LISREL. Graha IImu.

Sugiyono. (2016). Metode Penelitian Kuantitatif, Kualitatif dan R\&D. In Metode Penelitian Kuantitatif, Kualitatif dan $R$ \& $D$. Alfabeta. https://doi.org/10.1017/CBO9781 107415324.004

Turere, V. N. (2013). Pengaruh Pendidikan dan Pelatihan terhadap Peningkatan Kinerja
Karyawan Pada Balai Pelatihan Teknis Pertanian Kalasey. Pengaruh Pendidikan Dan Pelatihan Terhadap Peningkatan Kinerja Karyawan Pada Balai Pelatihan Teknis Pertanian Kalasey, 1 1(3). https://ejournal.unsrat.ac.id/index. php/emba/article/view/1368/1079

Weol, D. H. (2015). Pengaruh Lingkungan Kerja, Pelatihan dan Penempatan terhadap Kinerja Pegawai di Dinas Pendidikan Nasional Provinsi Sulawesi Utara. Pengaruh Lingkungan Kerja, Pelatihan Dan Penempatan Terhadap Kinerja Pegawai Di Dinas Pendidikan Nasional Provinsi Sulawesi Utara, 15(5).

Wirawan. (2015). Manajemen Sumber Daya Manusia Indonesia. Raja Grafindo Persada. 